\title{
PANORAMA GERAL SOBRE A GEOCONSERVAÇÃO EM NATAL (RN): AMEAÇAS À GEODIVERSIDADE IN SITU E EX SITU
}

\author{
M. L. N. SILVA* e M. A. L. NASCIMENTO \\ Departamento de Geologia, Universidade Federal do Rio Grande do Norte \\ nobre.mt@gmail.com*
}

Artigo submetido em junho/2016 e aceito em outubro/2016

DOI: 10.15628/holos.2016.4743

\section{RESUMO}

A geodiversidade é tida como a variedade de todos os elementos abióticos do planeta, como minerais, rochas, solos, além de elementos hidrológicos e pedológicos, entre outros. É um termo relativamente novo, em voga desde a década de 1990, mas que tem sido usado de forma crescente, sobretudo por estudos nas áreas de educação e divulgação das geociências. Os estudos no Brasil têm sido intensificados nos últimos 10 anos e têm colaborado também com ações de proteção ao meio ambiente, por meio da chamada geoconservação, que procura desenvolver o consumo sustentável dos elementos abióticos do planeta. Em Natal, capital do Rio Grande do Norte, além das belas paisagens, compostas por praias, dunas, falésias, rios, mangues e lagoas, existem diversos registros de usos dos recursos da geodiversidade, sobretudo, de rochas em monumentos e edifícios, históricos e recentes. Todos esses registros, naturais ou não, estão susceptíveis a ameaças que podem provocar desde pequenas modificações até a supressão das ocorrências. Essas ameaças são ampliadas nos centros urbanos, onde a necessidade por constantes mudanças e obras acaba agredindo o ambiente em que a cidade fora instalado. Assim, este trabalho apresenta conceitos de geodiversidade, geoconservação e geoturismo e mostra as principais ameaças à diversidade abiótica na cidade do Natal.

PALAVRAS-CHAVE: Geodiversidade, geoconservação, geoturismo, ecossistema, Natal.

\section{OVERVIEW ON THE GEOCONSERVATION IN NATAL (RN): THREATS TO THE IN SITU AND EX SITU GEODIVERSITY}

\begin{abstract}
The geodiversity is considered the variety of all abiotic elements of the planet, such as minerals, rocks, soils, also the hydrologic and pedological elements, among others. It is a relatively new term in vogue since the 1990s, but which has been used increasingly, especially for studies in the fields of education and dissemination of geosciences. Studies in Brazil have been intensified in the last 10 years and have also collaborated with environmental protection actions, through the geoconservation, which seeks to develop sustainable consumption of abiotic elements of the planet. In Natal, capital of Rio Grande do Norte, besides the beautiful
\end{abstract}

landscapes of beaches, dunes, cliffs, rivers, wetlands and lakes, there are many records of use of geodiversity resources, especially rocks in buildings and monuments, historical and recent. All these records, natural or not, are susceptible to threats that can result from small changes to the suppression of occurrences. These threats are increased in urban centers, where the need of constant change and constructions harm the environment in which the city had been installed. Therefore, this work presents concepts of geodiversity, geoconservation and geotourism and shows the main threats to abiotic diversity in the city of Natal.

KEYWORDS: Geodiversity, geoconservation, geotourism, ecosystem, Natal. 


\section{INTRODUÇÃO}

As geociências têm experimentado nas últimas três décadas uma expansão de novos conceitos e terminologias que interpretam o planeta como um organismo vivo e de dinâmica constante. Dentre as novas definições, são encontrados os termos "geodiversidade", "geoconservação" e "geoturismo". A partir dos quais a comunidade geocientífica passou a pensar e criar projetos de estudo, divulgação e proteção do meio abiótico, objetivando que sua exploração possa ser, em muitos casos, realizada de forma mais sustentável.

A geodiversidade compreende todas as formas e expressões abióticas da Terra, é, por si só, a moradia de todos os seres vivos e tem-se desenvolvido ao longo de 4,6 bilhões de anos. Geoconservação é tida como a proteção aos elementos abióticos por meio de ações de conscientização, divulgação e de estímulo de um consumo sustentável dos recursos naturais e tem como uma das principais ferramentas de divulgação/promoção o geoturismo, atividade econômica que vem sendo desenvolvida em todo o planeta lançando mão de atrativos naturais abióticos na realização de roteiros e atividades turísticas.

A cidade do Natal, capital do Rio Grande do Norte, está emoldurada por uma diversidade abiótica única, composta por campos dunares, falésias, rios, riachos, lagoas, recifes de arenito e manguezais.

No começo da história da cidade, havia vasta área de dunas vegetadas sem intervenção antrópica. Os arenitos calcíferos, dos arrecifes, e ferruginosos, da Formação Barreiras, encontrados nas praias eram elementos de grande importância na representação cartográfica da área e nas construções da época, o que caracteriza uma arquitetura vernacular, em que os recursos locais são utilizados nas edificações.

Com o passar dos séculos, a relação da comunidade local com o ambiente natural da cidade foi sendo modificada, as praias passaram a ser mais valorizadas, até serem hoje as regiões mais cobiçadas. Entretanto, o que permanece mesmo atualmente é a importância e imponência dos recursos da geodiversidade na capital potiguar.

A diversidade abiótica em Natal, assim como em todo o mundo, possui valores associados, que são caracterizados por metodologias apresentadas na literatura especializada. A definição de valores para os locais é ferramenta fundamental no embasamento a ações de proteção, que compõem, para o meio abiótico, a geoconservação.

Em Natal, alguns locais em que elementos da geodiversidade possuem destaque sofrem constantemente com ameaças que vão desde pichações a poluição, por agentes públicos ou algum indivíduo da comunidade. Estas ameaças podem suprimir e descaracterizar a geodiversidade local e precisam ser mitigadas e inibidas.

Por tal razão, este trabalho apresenta as principais ameaças à geodiversidade natalense, seja ela ocorrendo como representante do patrimônio natural da cidade ou como um constituinte do patrimônio histórico/cultural da comunidade local. 


\title{
2 GEODIVERSIDADE E GEOCONSERVAÇÃO
}

A geodiversidade é um termo desenvolvido no âmbito das geociências desde a década de 1990. Apesar de ainda pouco conhecida pelo público leigo, tem sido bastante aplicado nos estudos que envolvam a divulgação do conhecimento das ciências da Terra, assim como no embasamento de ações de proteção dos recursos abióticos do planeta.

Atualmente, a terminologia envolvida pela geodiversidade é estudada, principalmente, por geólogos e geógrafos em todo o mundo, tendo, entretanto, maior desenvolvimento no hemisfério norte. Gray (2013), em uma das principais publicações específicas da área, define geodiversidade como:

\begin{abstract}
"a variedade natural (diversidade) de elementos geológicos (rochas, minerais, fósseis), geomorfológicos (formas de relevo, topografia, processos físicos), do solo e hidrológicos. Isso inclui suas assembleias, estruturas, sistemas e contribuições para as paisagens" (Gray, 2013, p. 12).
\end{abstract}

Apesar de ser um conceito relativamente novo, os recursos da geodiversidade estão presentes em toda a dimensão do planeta, tendo, ao longo da história, importância no desenvolvimento da biodiversidade.

Brilha (2005) e Galopim de Carvalho (2007) mostram que até mesmo a evolução das civilizações humanas está condicionada à presença da geodiversidade, algo que é exemplificado por exemplo, pelo uso do sílex nos primórdios da Idade da Pedra como instrumento de caça, auxiliando a sobrevivência dos primeiros homens.

As cidades, ao longo dos séculos, foram estabelecidas nos ambientes naturais que favoreciam, inicialmente, sua proteção e manutenção agrícola. Ambientes próximos aos litorais foram utilizados na instalação de centros urbanos mercantilistas a partir do final do século XIV. As definições de urbanismo que surgiram após a Revolução Industrial modificaram as necessidades, formas e construções das cidades, que se favoreceram dos recursos naturais disponíveis para seu desenvolvimento. Em todas essas situações, a geodiversidade esteve atrelada ao início e expansão da urbis no planeta (SILVA, 2016).

E essa diversidade abiótica precisa ser protegida e ter um consumo sustentável incentivado, assim como já está consagrado nas ações de proteção da biodiversidade. Afinal, os elementos abióticos da natureza são tão importantes para o ecossistema como os bióticos.

Isto se justifica, pois a relação da geodiversidade com o ecossistema se dá não somente porque o meio abiótico é o habitat dos seres vivos, mas também porque é responsável pela disponibilização de água doce, pela manutenção da qualidade da água e ar, pela formação dos solos e pela reciclagem de nutrientes para a produção de comida. É também fundamental para o desenvolvimento das atividades do ser humano, como a exploração mineral que é responsável pelo provimento de milhares de espécimes minerais utilizadas nas mais diversas aplicações, desde confecção de roupas a fabricação de baterias que movem milhões de máquinas em todo o mundo (HJORT et al., 2015).

Para se proteger um recurso ou região natural no planeta precisa-se inicialmente, realizar um inventário com valoração dos elementos que são encontrados. Assim, diversos sistemas de valores são encontrados na literatura. Gray (2013) apresenta um modelo baseado no que foi 
definido pela Avaliação Ecossistêmica do Milênio, determinando serviços, bens e processos da geodiversidade.

A classificação do autor define 1 valor maior, chamado de intrínseco (ou existência), e 5 serviços (provisão, regulação, cultural, suporte e conhecimento). Têm-se ainda 25 bens e processos derivados da geodiversidade que são relacionados por ele a esses serviços. O trabalho de Silva (2016) compilou esse sistema sob a forma de um diagrama, que é apresentado na figura 1.

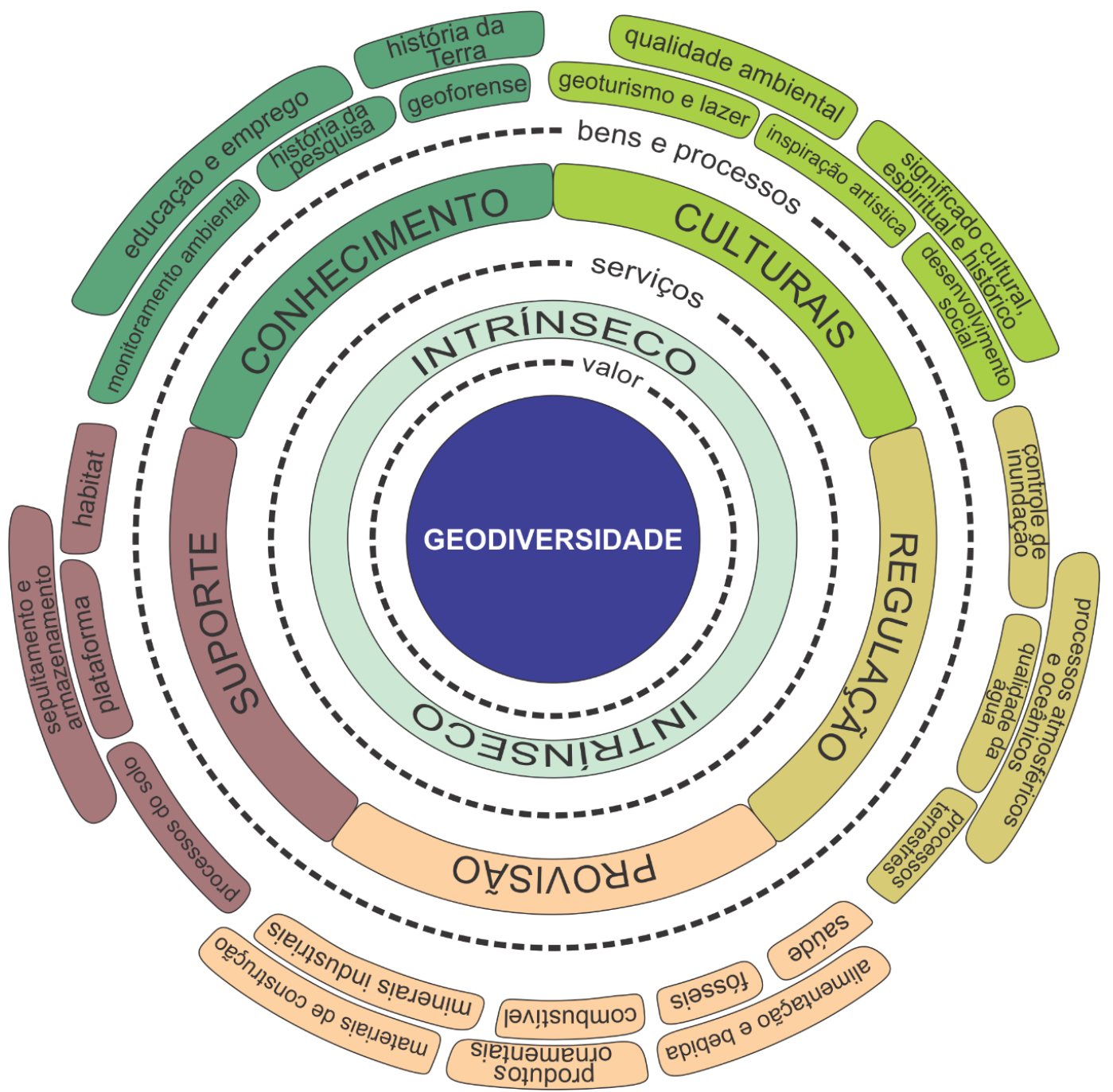

Figura 1: Sistema de valoração da geodiversidade sensu Murray Gray com enfoque nos serviços ecossistêmicos. Fonte: Silva (2016)

Os sistemas de valoração e classificação dos lugares de geodiversidade têm por objetivo auxiliar projetos de manejo das áreas, de forma a promover sua conservação ou exploração sustentável.

Uma vez que os locais que possuem algum valor associado sofrem alguma ameaça, seja ela natural, catastrófica ou antrópica, passa a existir a necessidade de conservação de seus recursos e elementos.

Gray (2013) coloca que as principais ameaças para a geodiversidade do planeta estão associadas à mineração, expansão urbana, projetos de engenharia na rede hidrográfica, aterros 
sanitários, agropecuária, atividades militares, retirada de espécimes minerais, atividades turísticas sem mitigação dos impactos, entre outras formas de gestão dos espaços.

Dessas ações, a geodiversidade pode ser impactada das seguintes formas:

- Perda total de um recurso da geodiversidade;

- Perda parcial ou dano físico;

- Perda de visibilidade ou intervisibilidade;

- Perda de acesso;

- Interrupção dos processos naturais;

- Poluição;

- Impacto visual

Uma vez que tais impactos podem acarretar perdas imensuráveis para as geociências, assim como para toda a sociedade, desenvolveu-se, concomitantemente com o termo geodiversidade, o termo geoconservação, que almeja a conservação da diversidade abiótica do planeta.

Entretanto, como muitos dos recursos abióticos terrestres são fundamentais para a vida humana, pretende-se, com a valoração e classificação dos lugares, proteger aqueles locais com geodiversidade excepcional, ou o patrimônio geológico da Terra.

As medidas de proteção da geodiversidade podem advir da "criação de leis e programas específicos para o patrimônio geológico e/ou por meio da sensibilização do público sobre a importância deste patrimônio, utilizando-o para o turismo" (NASCIMENTO et al., 2008).

Programas de proteção à geodiversidade são registrados no mundo, sobretudo no hemisfério norte. O Programa de Geoparques da UNESCO (figura 2) é uma das principais ações de proteção da geodiversidade in situ, atualmente contando com 120 geoparques em 33 países.

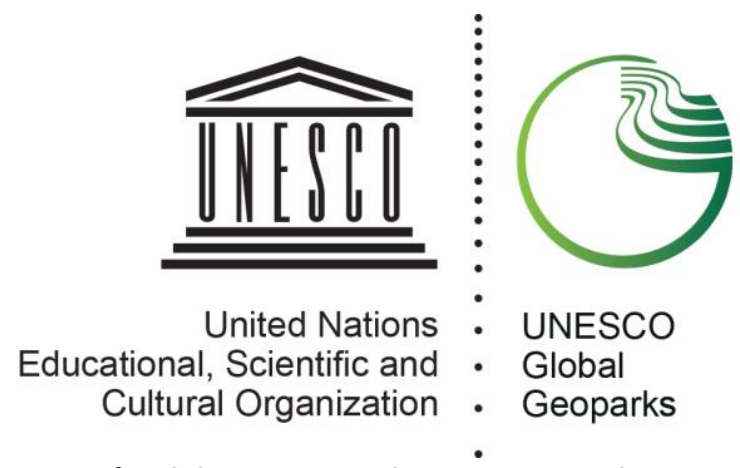

Figura 2: Logomarca oficial do Programa de Geoparques da UNESCO. Fonte: unesco.org

O Programa de Geoparques da UNESCO começou a ser criado em 2000 na Europa (com 4 geoparques) e três anos depois já possuía 25 geoparques membros, sendo 8 na China. Os Geoparques têm como foco atividades relacionadas à educação, ciência, turismo, cultura, desenvolvimento social e proteção das mulheres. São realizadas nos geoparques ações de exploração sustentável da geodiversidade, por meio do geoturismo, artesanato e gastronomia, além de projetos de geociências para a sociedade, que procuram envolver a comunidade local no desenvolvimento e manutenção do geoparque, de forma que as ações de proteção tragam benefícios para todos.

O Brasil conta com um geoparque da UNESCO desde 2006, na região do Araripe-CE. Entretanto, o Serviço Geológico do Brasil (CPRM) possui um programa de gestão chamado Geoparques do Brasil, que consta de 37 propostas. 
Projetos como Caminhos Geológicos (Rio de Janeiro), Sítios Geológicos (Paraná), Caminhos Geológicos da Bahia (Bahia) e Monumentos Geológicos (Rio Grande do Norte) foram ações implementadas desde 2003 que procuraram promover também a geodiversidade por meio da educação para toda a sociedade (MANSUR et al., 2013).

Carvalhido et al. (2016) mostram que as estratégias ideais de geoconservação devem ser implementadas pelo poder público, em suas diferentes esferas, de forma a colaborar com as atividades de gestão dos recursos naturais com ações que também possam incentivar a economia, através do viés turístico, por exemplo.

Ou seja, todas as atividades que visam a geoconservação devem envolver a sociedade por meio da educação, cultura, turismo e economia. Essas ações de divulgação e proteção da geodiversidade podem ser desenvolvidas para as regiões que possuem elementos in situ (aqueles que ocorrem no local de formação) ou ex situ (aqueles que são transferidos de seu local de formação para outro), mas devem sempre focar na proteção do patrimônio geológico, na tradução do conhecimento geológico para a sociedade leiga e no envolvimento desta sociedade na geoconservação.

Em relação à geodiversidade da cidade do Natal, que teve seus valores qualitativos e serviços identificados no trabalho de Silva (2016), pode-se observar que as duas vertentes presentes, in situ e ex situ, sofrem com ações que ameaçam o patrimônio natural e cultural local.

A necessidade de conservação da geodiversidade de um lugar está no fato de que muitos dos recursos existentes são esgotáveis e, ao mesmo tempo, únicos. É preciso, portanto, haver uso sustentável da geodiversidade mundial, conservando sempre aqueles locais que possuem um alto valor, seja ele científico, cultural ou simplesmente turístico devido à seu aspecto visual. A avaliação destes locais passa por uma valoração qualitativa e quantitativa, além de uma forte participação dos gestores e população em geral.

Ações de proteção ao meio abiótico in situ estão consagradas por meio do Programa Global Geoparques da UNESCO, mas também devem ser desenvolvidas em localidades menores como Natal, em que, apesar de muitos dos recursos da geodiversidade estarem contidos em Zonas de Proteção Ambiental, ainda se observa agressões que desmontam e descaracterizam os ambientes naturais ou monumentos e edificações que fizeram uso de rochas em suas construções.

A proteção das expressões ex situ da geodiversidade está muito ligada à gestão do patrimônio cultural, que procura proteger os valores deste patrimônio, agregando e expandindo benefícios sociais, econômicos e ambientais (UNESCO, 2016).

Neste trabalho são apresentadas a seguir as principais ameaças à geodiversidade na cidade do Natal, seja ela in situ ou ex situ, como forma de identificar os principais problemas à geoconservação local.

Soluções para as problemáticas aqui observadas demandam legislações específicas, assim como programas de educação que envolvam a temática da geodiversidade e o usufruto sustentável, por meio da população em seu cotidiano, das paisagens, praias, monumentos e toda e qualquer expressão que a geodiversidade possa ter. 


\section{AMEAÇAS À GEODIVERSIDADE IN SITU}

Em relação à geodiversidade in situ, a maior problemática se dá pela poluição dos ambientes abióticos. Casos explícitos em Natal são a quantidade de lixo jogada nos mangues (figura 3), que acaba contaminando o substrato dos depósitos flúvio-marinhos, prejudicando também a biodiversidade típica deste local. Na região da Via Costeira, canais jogam efluentes na praia em direção ao oceano (figura 4), provocando, além da poluição do mar e da linha de costa, erosão regressiva nas dunas frontais.

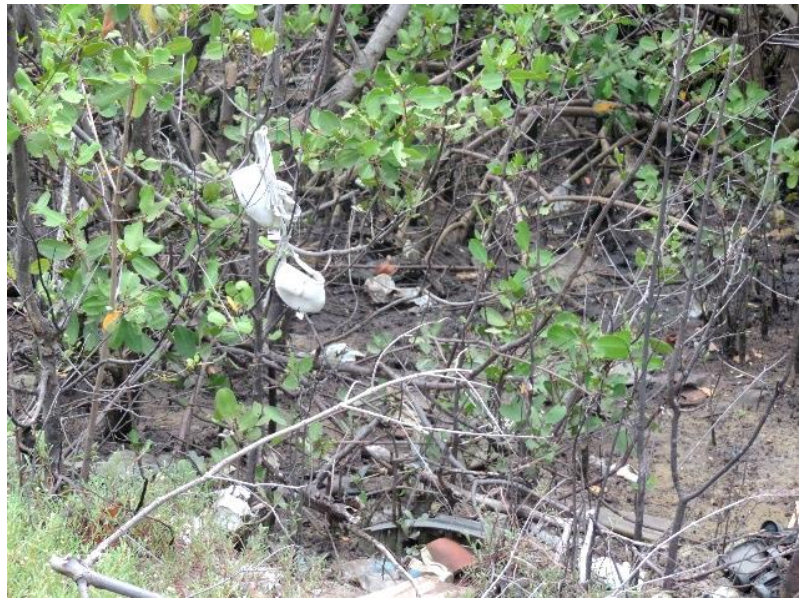

Figura 3: Lixo jogado no manguezal localizado próximo à praia da Redinha. Foto: Matheus Lisboa

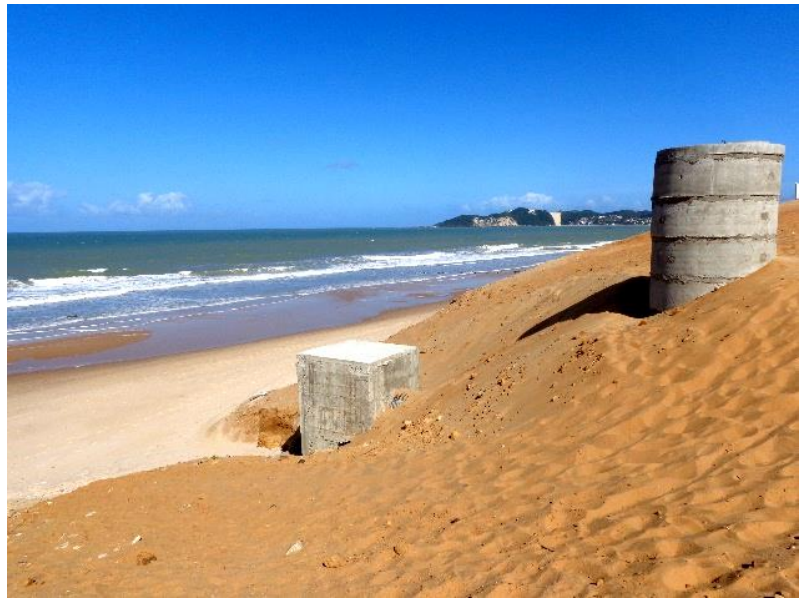

Figura 4: Desembocadura de canal de escoamento de efluentes na Via Costeira. Foto: Matheus Lisboa

Obras de enrocamento construídas, sobretudo, nas praias de Areia Preta e Ponta Negra (figura 5) modificaram a dinâmica natural nestas duas áreas da costa natalense, alterando o fluxo sedimentar e de correntes marítimas. Há regiões hoje, no litoral de Natal, em que há um balanço negativo no fluxo de sedimentos, provocado por essas obras de enrocamento.

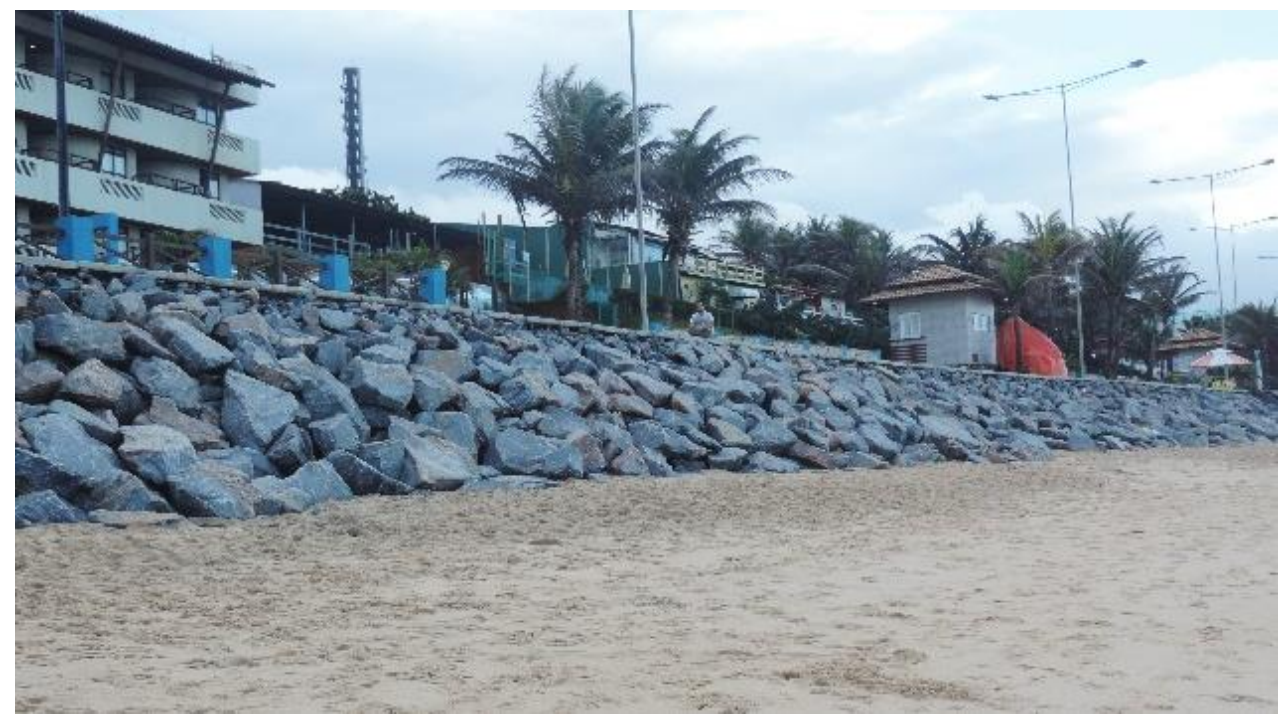

Figura 5: Fotografia de parte do enrocamento na praia de Ponta Negra. Foto: Matheus Lisboa

Logo, este tipo de obra pode ser caracterizado também como uma ameaça à geodiversidade, especificamente àquela que ocorre de forma natural na cidade, de maneira in situ. 
Outra ameaça à geodiversidade que tem sido evidente na cidade do Natal é a ocupação de margens de rios e lagoas, de faixas de praia e de dunas de forma irregular. Ao longo dos anos, observou-se forte especulação imobiliária em torno desses locais, tidas como privilegiadas, o que demandou diversos protestos por pesquisadores de diversas áreas, além de processos na justiça. Entretanto, muitas comunidades de baixa renda acabaram por se estabelecer nestas regiões, como mostra a figura 6 .

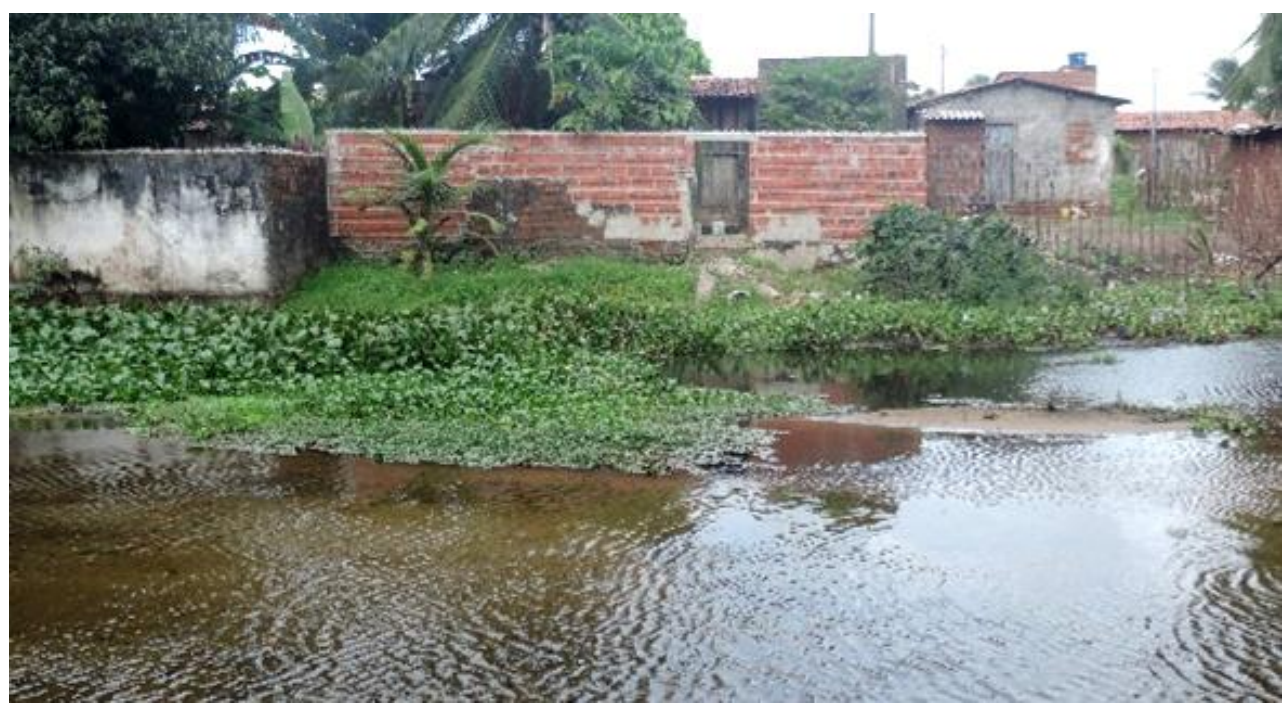

Figura 6: Ocupações irregulares na margem do rio Doce, zona norte de Natal. Foto: Matheus Lisboa

Estas ocupações, sobretudo com o viés de especulação imobiliária são a maior ameaça à geodiversidade in situ na cidade do Natal. Ainda que diversas ações públicas de parte, por exemplo, do Ministério Público tentem evitar grandes empreendimentos que possam representar agressões consideráveis, sobretudo, às paisagens de Natal, observa-se que existem hoje condomínios residenciais construídos sobre as dunas de algumas Zonas de Proteção Ambiental e esta é apenas uma das formas que a indústria privada de venda de espaços residenciais ou comerciais, que também ocorre pela ocupação das margens de rios, praias e lagoas na cidade objetivo de uso desses locais como molduras para as construções modernas de espigões ou condomínios residenciais.com o

O fato é que a beleza paisagística da cidade, que é constituída essencialmente de elementos de natureza abiótica, que é a geodiversidade local, é atrativo primário para os empreendimentos na cidade e representa também um atrativo econômico para as obras. Trabalhos como os de Nobre (2001) e Bentes e Trindade (2008) versam sobre os aspectos da especulação imobiliária que afetam o ambiente natural da cidade.

Disto posto, é preciso que haja um desenvolvimento e divulgação maiores do entendimento da geodiversidade local da cidade do Natal de forma que essas ameaças sejam, ao menos, mitigadas, embasando ações de proteção eficazes e que atitudes punitivas possam ser implementadas na forma da legislação vigente, visando também a recuperação dos ambientes afetados. 


\section{AMEAÇAS À GEODIVERSIDADE EX SITU}

Quando se trata da geodiversidade ex situ, observa-se que ela pode ser encontrada nos logradouros, monumentos e edificações que utilizem algum elemento da geodiversidade em sua ornamentação ou construção, principalmente na forma de blocos de rochas. A ameaça a esse patrimônio cultural, que em Natal datam desde o século XVII até reformas mais recentes, se caracterizam como ameaças também à geodiversidade.

Carvalho (2010) e Silva (2016) identificam e descrevem os principais locais históricos onde também são encontrados registros de uso de rochas como um elemento construtivo, seja no calçamento de ruas, como representado pelo calçamento "pé-de-moleque" feito com arenitos ferruginosos no Centro Histórico de Natal, ou como material de construção para as primeiras igrejas e edificações da cidade, que utilizaram blocos de arenitos calcíferos, retirados dos arrecifes do litoral natalense.

Já no início do século XX tem-se o uso de granitos, principalmente retirados em pedreiras no município de Macaíba, em monumentos espalhados por bairros como Cidade Alta, Ribeira, Alecrim e Petrópolis. Mais recentemente, a diversidade litológica utilizada em obras na cidade passou a ser composta também, por exemplo, por calcários, mármores, ardósias, ortognaisses, e migmatitos.

Disto, tem-se que pichações nos monumentos, como é identificado no monumento aos mártires (figura 7), no Centro Histórico, e no monumento a Pedro Velho, na Praça Cívica, são uma das principais ameaças ao patrimônio. Em relação à geodiversidade, a tinta que é utilizada para realizar o ato infracional acaba cobrindo as rochas e seus minerais, dificultado sua descrição e descaracterizando-a.

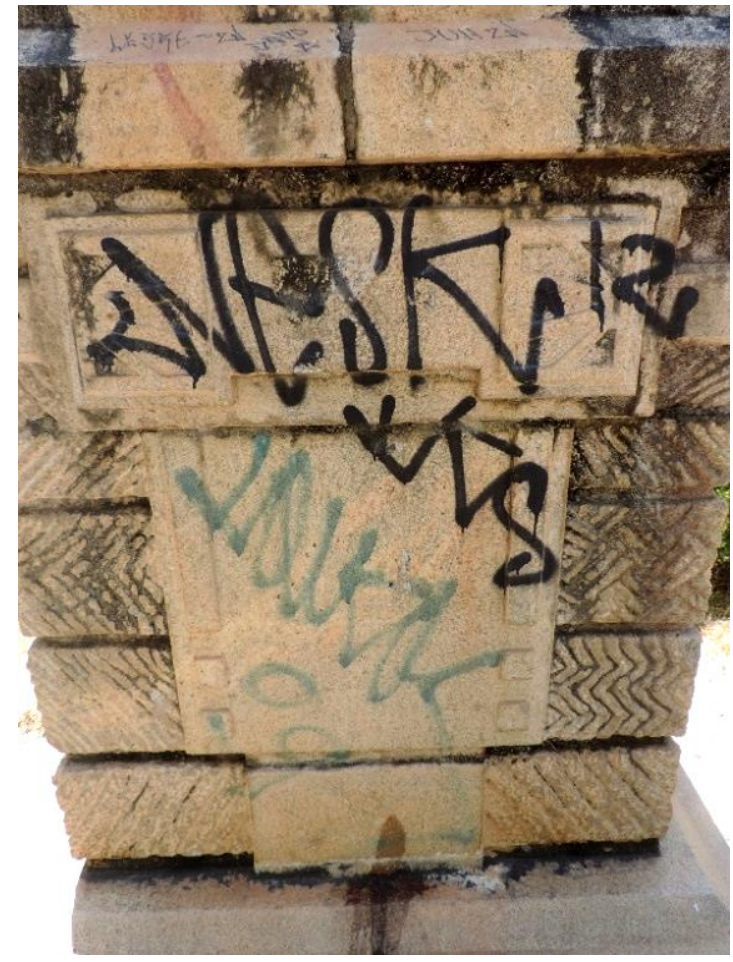

Figura 7: Detalhe de pichação feita no monumento aos mártires, na praça André de Albuquerque. Foto: Matheus Lisboa

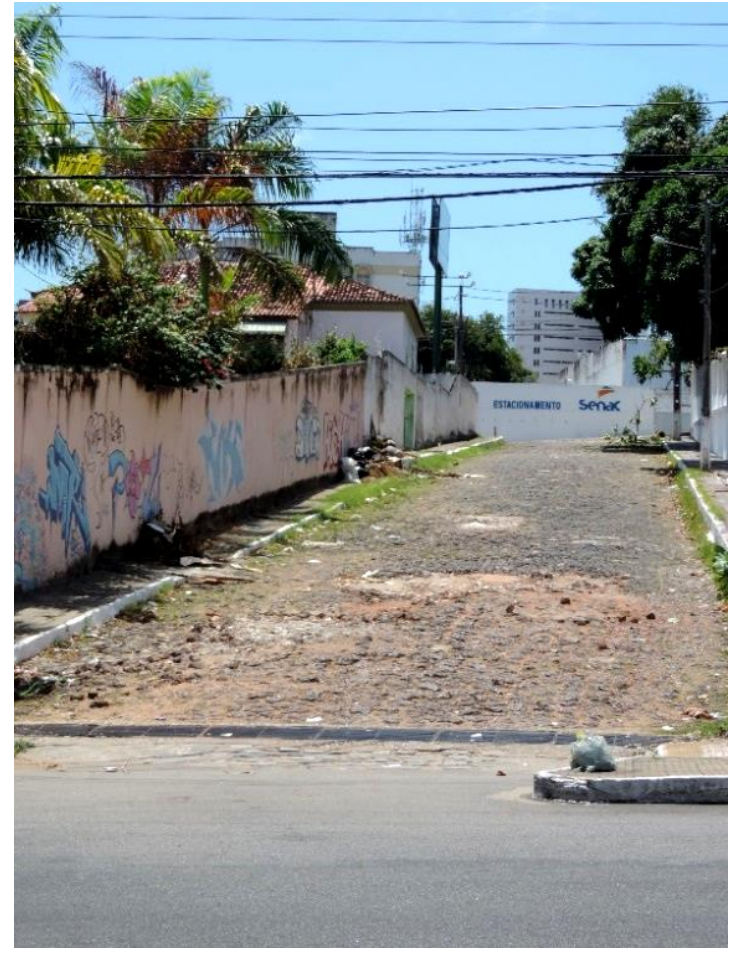

Figura 8: Fotografia da Travessa Pax em outubro de 2015, destaque para os blocos de arenito soltos. Foto: Matheus Lisboa 
O tráfego de carros na Travessa Pax, maior registro de calçamento "pé-de-moleque" feito com arenitos ferruginosos da Formação Barreiras em Natal, acaba por retirar blocos da rua (figura 8). Da travessa, que é tombada pela Fundação José Augusto desde 2007 (Decreto Normativo 19.930/2007), é retirado, portanto, um elemento da geodiversidade de alto valor histórico de seu local de uso original. Lixo nas ruas também são ameaças que afetam o patrimônio cultural e os recursos abióticos utilizados.

Estes casos citados são, em geral, cometidos por algum individuo da comunidade, que se aproveita da ineficácia do setor público no que se refere à fiscalização e manutenção destes locais.

Entretanto, os próprios agentes públicos e privados que deveriam realizar a proteção destes locais, por descuido, desinteresse ou desconhecimento da importância do elemento da geodiversidade utilizado nos monumentos, acaba por desconsiderá-los em oportunidades de reformas, como é o caso das Igrejas de Santo Antônio e de Nossa Senhora da Apresentação, no bairro da Cidade Alta (figuras 9 e 10).

Durante obras de reparo nas duas construções, foi posto de lado o fato do uso histórico de blocos de arenito calcífero nas porteiras e fachadas, que remonta ao século XVIII, e houve a colocação de concreto como forma de substituição da rocha.

Sabe-se que há diversos corpos de recifes de arenito ao longo do litoral natalense, de onde poderiam ter sido retirados pequenos blocos para serem trabalhados em cantaria de forma a fazer a reposição correta do material utilizado. Esta substituição que ocorreu caracteriza-se também como uma ameaça à geodiversidade, porque é perdido o registro de seu uso em uma área de importância histórica para a cidade.

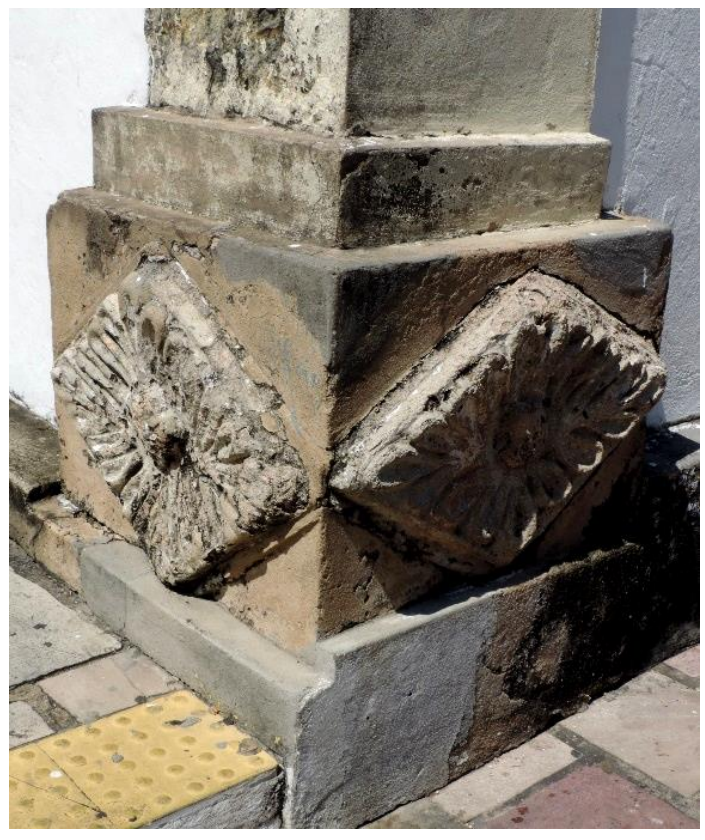

Figura 9: Detalhe de coluna na Igreja de Santo Antônio com base refeita em concreto. Foto: Matheus Lisboa

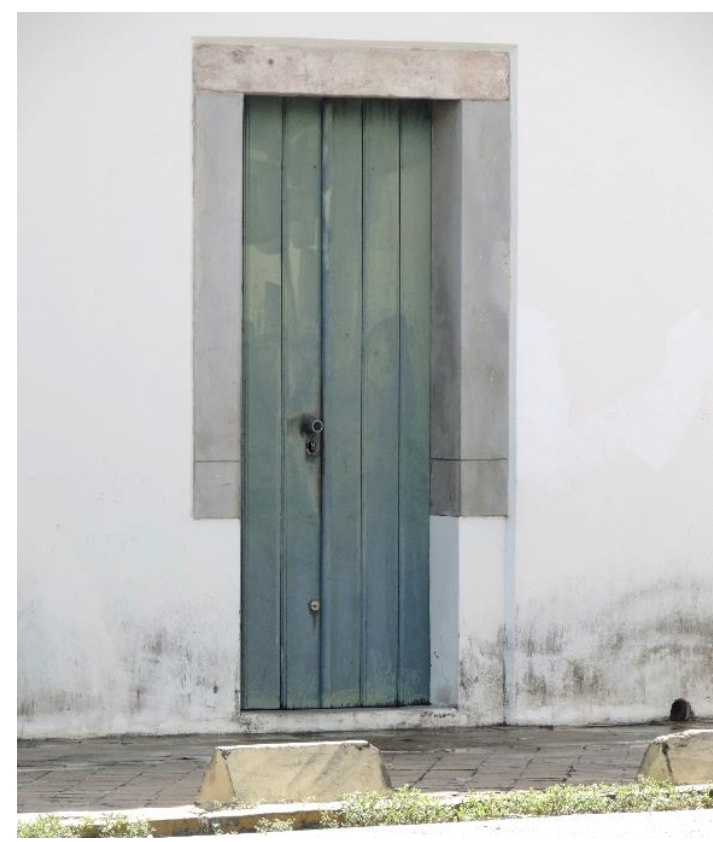

Figura 10: Porta lateral na Igreja de Nsa Sra da Apresentação com colunas refeitas em concreto. Foto: Matheus Lisboa

Ameaça maior ainda é o descuido por parte dos gestores principais do município, que compõem a Prefeitura Municipal, em momento de intencional "limpeza" dos monumentos a Augusto Severo, no bairro da Ribeira, e a Dom Pedro II, em praça homônima no bairro do Alecrim. 
A solução para pichações e sujeira nestes dois locais foi, em outubro de 2015 , ter sido feita a pintura completa dos monumentos com uma tinta que não apenas cobriu os dois pedestais, mas cobriu as rochas utilizadas e seus minerais, registros não apenas da história do homem e da cidade, mas também de milhões de anos do Planeta Terra.

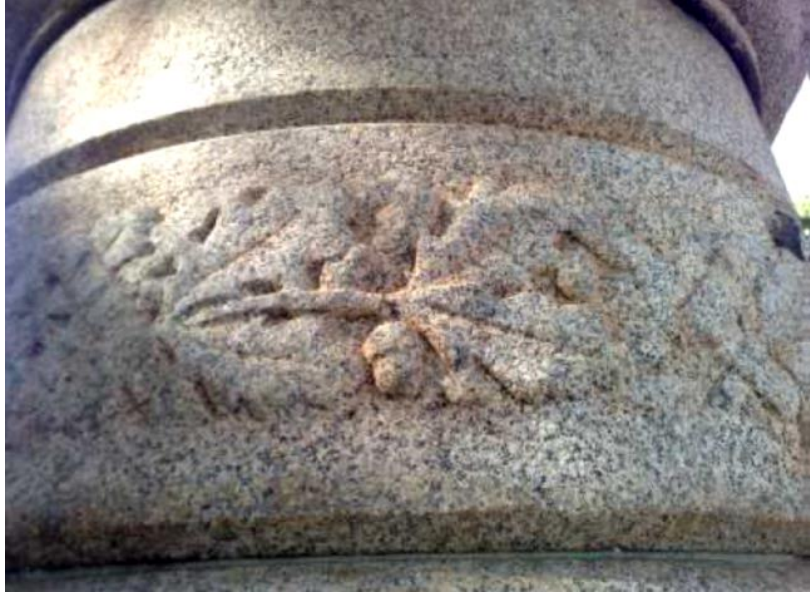

Figura 11: Pedestal de granito com trabalho em cantaria no monumento de Augusto Severo, em 2010. Fonte: Carvalho (2010)

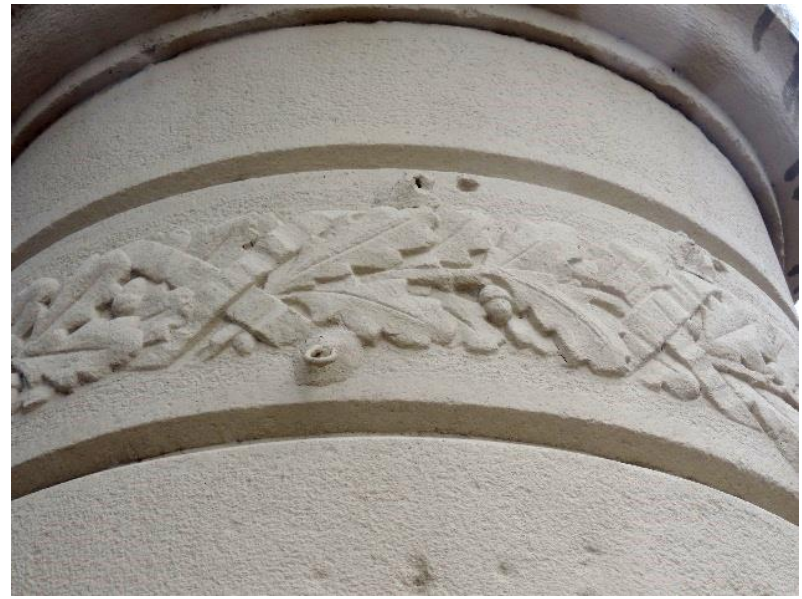

Figura 12: Pedestal do monumento a Augusto Severo após a pintura pela Prefeitura, em 2015.

Foto: Matheus Lisboa

As figuras 11 e 12 mostram um comparativo do pedestal de granito no monumento a Augusto Severo, antes e depois de ter sido pintado. Após a pintura, o monumento perdeu, de certa forma, sua beleza e se assemelhou muito a algo construído com concreto.

Como se observa, todos os casos em que houve agressão ao patrimônio cultural local que lança mão de algum elemento da geodiversidade em sua composição arquitetônica, parece haver certo desconhecimento da importância daquele recurso.

Soluções seriam, possivelmente, o incentivo à educação ambiental com enfoque na geodiversidade, além de promoção das geociências junto à sociedade, bem como o entendimento do recurso abiótico junto ao patrimônio cultural, assim incentivando também a educação patrimonial.

\section{CONCLUSÕES}

Natal é uma cidade em que a geodiversidade é proeminente em suas paisagens, sendo também encontrada como elemento construtivo em regiões e edificações históricas, erguidas desde o século XVII.

Essa geodiversidade, no entanto, sofre com ameaças que são responsáveis não somente por poluição que afeta à população, mas que agride o ambiente natural onde a cidade foi erguida e que é ainda hoje relevante para o desenvolvimento desta ao longo dos séculos.

Disto posto, é fundamental que o conceito da geodiversidade seja divulgado e mais amplamente utilizado nos estudos que versem sobre a proteção do meio ambiente, de forma a criar a consciência na comunidade científica e leiga local de que os recursos abióticos do planeta são tão importantes quanto os seres vivos, fauna e flora, amplamente estudados e protegidos, bem como também amplamente usado em estudos do patrimônio cultural quando neste são 
encontrados recursos da geodiversidade, como é o caso do uso de material pétreo em inúmeras construções.

\section{REFERÊNCIAS BIBLIOGRÁFICAS}

1. BENTES, D., TRINDADE, M. A. S. F. Zonas Especiais de Interesse Social - ZEIS - e Grandes Empreendimentos: resistência de territórios populares e elementos para inclusão sócioterritorial no litoral potiguar. Revista da FARN, v.7, n.2, p.143-159, 2008.

2. BRILHA, J. 2005. Património Geológico e Geoconservação: a conservação da natureza na sua vertente geológica. Braga, Palimage Editores, 183p.

3. CARVALHIDO, R. J., BRILHA, J. B., PEREIRA, D. I. Designation of Natural Monuments by the Local Administration: the Example of Viana do Castelo Municipality and its Engagement with Geoconservation (NW Portugal). Geoheritage, 2016.

4. CARVAlHO, H. L. 2010. Patrimônio Geológico do Centro Histórico de Natal. Natal, 2010. Relatório de Graduação, Departamento de Geologia, Universidade Federal do Rio Grande do Norte, 105p, 2010.

5. DECRETO NORMATIVO № 19.930, de 25 de julho de 2007. Tomba a Travessa Pax localizado no Bairro da Ribeira, localizada em Natal/RN. Diário Oficial do Estado, № 11525, p.1.

6. GALOPIM DE CARVAlHo, A. M. Como Bola Colorida, a Terra, Património da Humanidade. Lisboa, Âncora Editora, 245p, 2007.

7. GRAY, M. Geodiversity: valuing and conserving abiotic nature. 2a edição. Chichester, John Wiley \& Sons, 495p, 2013.

8. HJORT, J., GORDON, J. E., GRAY, M., HUNTER JR., M. L. Why Geodiversity Matters in Valuing Nature's Stage. Conservation Biology, v.29, n.3, p. 630-639, 2015.

9. MANSUR, K. L., ROCHA, A. J. D., PEDREIRA, A., SCHOBBENHAUS, C., SALAMUNI, E., ERTHAL, F. C., PIEKARZ, G., WINGE, M., NASCIMENTO, M. A. L., RIBEIRO, R. R. Iniciativas institucionais de valorização do patrimônio geológico do Brasil. Boletim Paranaense de Geociências, v.70, p. 0227, 2013.

10. NASCIMENTO, M. A. L., RUCHKYS, U. A., MANTESSO-NETO, V. Geodiversidade, Geoconservação e Geoturismo: trinômio importante para a proteção do patrimônio geológico. Natal, Sociedade Brasileira de Geologia, 84p, 2008.

11. NOBRE, P. J. L. Entre o cartão-postal e a cidade-real: um estudo sobre paisagem e produção imobiliária em Natal/RN. Natal, 2001. Dissertação de Mestrado, Programa de Pós-Graduação em Arquitetura e Urbanismo, Universidade Federal do Rio Grande do Norte, 156p, 2001.

12. UNESCO - Organização das Nações Unidas para a Educação, a Ciências e a Cultura. Manual de Referência do Patrimônio Mundial. Paris, IPHAN, 163p, 2016.

13. SILVA, M.L.N. Geodiversidade da Cidade do Natal: Valores, Classificações e Ameaças. Natal, 170p. Monografia de Conclusão de Curso, Curso de Geologia, Centro de Ciências Exatas e da Terra Universidade Federal do Rio Grande do Norte, 170p, 2016. 